\title{
Expression of epidermal growth factor, transforming growth factor- $\beta 1$ and adiponectin in nipple aspirate fluid and plasma of pre and post-menopausal women
}

\author{
Jessica A Miller ${ }^{1 *}$, Patricia A Thompson¹, Iman A Hakim², Ana Maria Lopez ${ }^{1}$, Cynthia A Thomson², \\ Chiu-Hsieh $\mathrm{Hsu}^{2}$ and H-H Sherry Chow ${ }^{1}$
}

\begin{abstract}
Background: Nipple aspirate fluid (NAF) contains large amounts of protein thought to reflect the microenvironment of the breast, and is of interest in breast cancer prevention research. The correlation between specific NAF proteins to plasma concentrations have not been well studied in healthy women. We collected matched NAF and plasma from 43 healthy pre and postmenopausal women participating in an early phase clinical study to compare the levels of putative cancer protein biomarkers. We compared baseline NAF and plasma levels of epidermal growth factor (EGF), transforming growth factor-beta 1 (TGF- $\beta 1$ ), and adiponectin and evaluated menopausal status and body mass index (BMI) as potential modifying factors.

Findings: NAF and plasma levels of EGF, TGF- $\beta 1$ and adiponectin were not correlated. EGF and TGF- $\beta 1$ levels in NAF of premenopausal women were significantly higher than postmenopausal women $\left(P^{\prime} s<0.01\right)$. These differences by menopausal status were not observed in plasma. Both NAF and plasma adiponectin levels were non-significantly higher in postmenopausal women. NAF biomarker levels were not associated with BMI whereas plasma EGF, TGF- $\beta 1$ and adiponectin levels in postmenopausal women were all inversely correlated with BMI $\left(P^{\prime} \mathrm{s}<0.05\right)$.

Conclusions: Protein biomarkers differ significantly between NAF and plasma and are affected differently by both $\mathrm{BMI}$ and menopausal status. This study demonstrates important differences in biological information gained by characterizing biomarkers in NAF compared to plasma and suggests each sample source may independently inform on breast cancer risk.
\end{abstract}

\section{Findings} Introduction

Nipple aspirate fluid (NAF) is a rich source of protein postulated to more closely reflect the local breast microenvironment than plasma. Petrakis et al. [1] showed that simply producing NAF doubled a woman's risk of breast cancer, which lead to a handful of studies using NAF as a source of breast tissue risk biomarkers [2-4]. The components of NAF are regularly metabolized and reabsorbed by the epithelial lining of the ductal/alveolar

\footnotetext{
* Correspondence: jam1@email.arizona.edu

'The University of Arizona Cancer Center, Tucson, AZ, USA

Full list of author information is available at the end of the article
}

system [5]. It is hypothesized that drug, protein and hormone levels in NAF more closely reflects breast tissue environment and exposures than plasma [6,7]. In women with breast cancer, Kuerer et al. found no association between serum and NAF levels of soluble Her-2/neu although the Her-2/neu levels between the affected and unaffected breasts were highly correlated [8]. Whether protein levels in NAF of healthy women are correlated with plasma is largely unknown.

In an effort to better understand the relatedness between plasma and NAF composition in healthy women, we conducted a correlative analysis of candidate breast cancer risk markers in matched NAF and plasma samples from healthy pre- and postmenopausal women

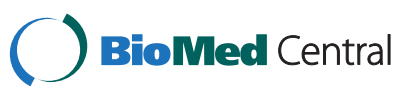

(c) 2013 Miller et al.; licensee BioMed Central Ltd. This is an Open Access article distributed under the terms of the Creative Commons Attribution License (http://creativecommons.org/licenses/by/2.0), which permits unrestricted use, distribution, and reproduction in any medium, provided the original work is properly cited. 
participating in a Phase I clinical trial. Here we report on our findings for biomarkers previously related to breast cancer, epidermal growth factor (EGF) [9], transforming growth factor-beta 1 (TGF- $\beta 1$ ) [10], and adiponectin [11].

\section{Study participants}

We recruited healthy women age 18-65 to a Phase I trial to evaluate the safety and feasibility of topical application of limonene as massage oil to the breast and to determine limonene levels in NAF. Details of the trial have been described elsewhere [12]. Participants were excluded if they were pregnant or breastfeeding, had invasive cancers within the past 5 years, participated in another clinical intervention trial within the past 3 months, had uncontrolled metabolic disorders, serious acute or chronic diseases, or were unable to produce NAF. The study was approved by the University of Arizona Human Subjects Committee and written consent was obtained from all participants.

\section{Sample collection}

Baseline (pre-intervention) NAF was collected via breast massage and a Medela breast pump into capillary tubes and immediately diluted in phosphate buffered saline (1:10). Baseline blood sample was collected into Vacutainer tubes containing sodium heparin and centrifuged for plasma separation. Plasma and diluted NAF were stored at $-80^{\circ} \mathrm{C}$ prior to analysis.

\section{Plasma and NAF biomarker analysis}

NAF and plasma EGF, TGF- $\beta 1$, and adiponectin were measured using ELISA based immunoassays (R\&D Systems, Minneapolis, MN, USA). Plasma samples were diluted prior to the analysis according to the manufacturer instructions for EGF and TGF- $\beta 1$, and were diluted 1:200 for the adiponectin assay. NAF samples were further diluted 1:100 - 400 for EGF, 1:20 - 40 for TGF- $\beta 1$ and 1:3 - 1:20 for adiponectin. Assays were linear over the concentration range of $3.9-250 \mathrm{pg} / \mathrm{mL}, 31.2-$ $2,000 \mathrm{pg} / \mathrm{mL}$, and 3.9 - $250 \mathrm{ng} / \mathrm{mL}$ for EGF, TGF- $\beta 1$, and adiponectin, respectively. Each sample was analyzed in duplicate for each assay (CVs $<10 \%$ for all assays).

\section{Statistical analysis}

Linear regression was performed to control for body mass index (BMI) while comparing differences between pre- and postmenopausal in protein biomarker levels in NAF as well as in plasma. Spearman correlation coefficients were derived to determine correlations between NAF and plasma biomarkers as well as BMI and NAF or plasma protein biomarkers. A $P$-value of $<0.05$ was considered statistically significant.

\section{Participant characteristics}

Matched baseline NAF and plasma samples were available from 16 premenopausal and 27 postmenopausal eligible women for the cross-sectional analysis; demographics are presented in Table 1.

\section{Plasma and NAF biomarker levels by menopausal status} Participants produced a wide range of NAF volume $(3-50 \mu \mathrm{L})$ and in some participants there was insufficient NAF sample volume for all three biomarker measurements, yielding 33, 35 and 28 pairs of plasma and NAF measurements for EGF, TGF- $\beta 1$ and adiponectin, respectively. The total protein concentration in NAF also varied widely among the study participants (13 - 101 $\mathrm{mg} / \mathrm{mL}$ ). Therefore, all NAF protein biomarker measurements were normalized by the total protein concentration. Figure 1 illustrates matched NAF and plasma biomarker levels by menopausal status (mean \pm SD presented in Additional file 1: Table S1). We corrected for BMI in all analyses. Postmenopausal women had significantly lower EGF $(P=0.004)$ and TGF- $\beta 1 \quad(P=0.01)$ levels in NAF when compared to premenopausal women. Plasma EGF levels were non-significantly higher in premenopausal women compared to postmenopausal while plasma TGF- $\beta 1$ levels were not different $(P=0.06$ and $P=0.69$, respectively). Adiponectin levels were nonsignificantly higher in postmenopausal women in NAF $(P=0.15)$ as well as plasma $(P=0.07)$.

\section{Plasma and NAF biomarker correlations and relationship to BMI}

None of the plasma biomarker levels were statistically significantly correlated to NAF levels (Table 2; Additional file 1: Figure S1). We also examined the correlation between levels of EGF, TGF- $\beta 1$, and adiponectin and BMI by menopausal status (Table 3: Additional file 1: Figure S2). NAF biomarkers were not significantly correlated to BMI in either pre- or postmenopausal women. Plasma measures of EGF, TGF- $\beta 1$ and adiponectin were all significantly inversely correlated with BMI in postmenopausal women $(P=0.003, P<0.001$, and $P=0.05$; respectively). In

Table 1 Participant demographics

\begin{tabular}{lcc}
\hline & $\begin{array}{c}\text { Premenopausal } \\
\text { women }(\mathbf{N}=16)\end{array}$ & $\begin{array}{c}\text { Postmenopausal } \\
\text { women }(\mathbf{N}=\mathbf{2 7})\end{array}$ \\
\hline Age & $45(41.4 \pm 10.9)^{\mathrm{a}}$ & $56.0(56.2 \pm 5.0)^{\mathrm{a}}$ \\
Body Mass Index $\left(\mathrm{kg} / \mathrm{m}^{2}\right)$ & $25.3(27.3 \pm 6.0)^{\mathrm{a}}$ & $25.1(25.7 \pm 4.6)^{\mathrm{a}}$ \\
Race/Ethnicity: $n(\%)$ & & \\
Caucasian & $15(93.7)$ & $24(88.9)$ \\
Pacific Islander & $1(6.3)$ & $0(0.0)$ \\
Native American & $1(6.3)$ & $1(3.7)$ \\
Black & $0(0.0)$ & $2(7.4)$ \\
\hline
\end{tabular}

${ }^{a}$ median (mean $\left.\pm S D\right)$. 


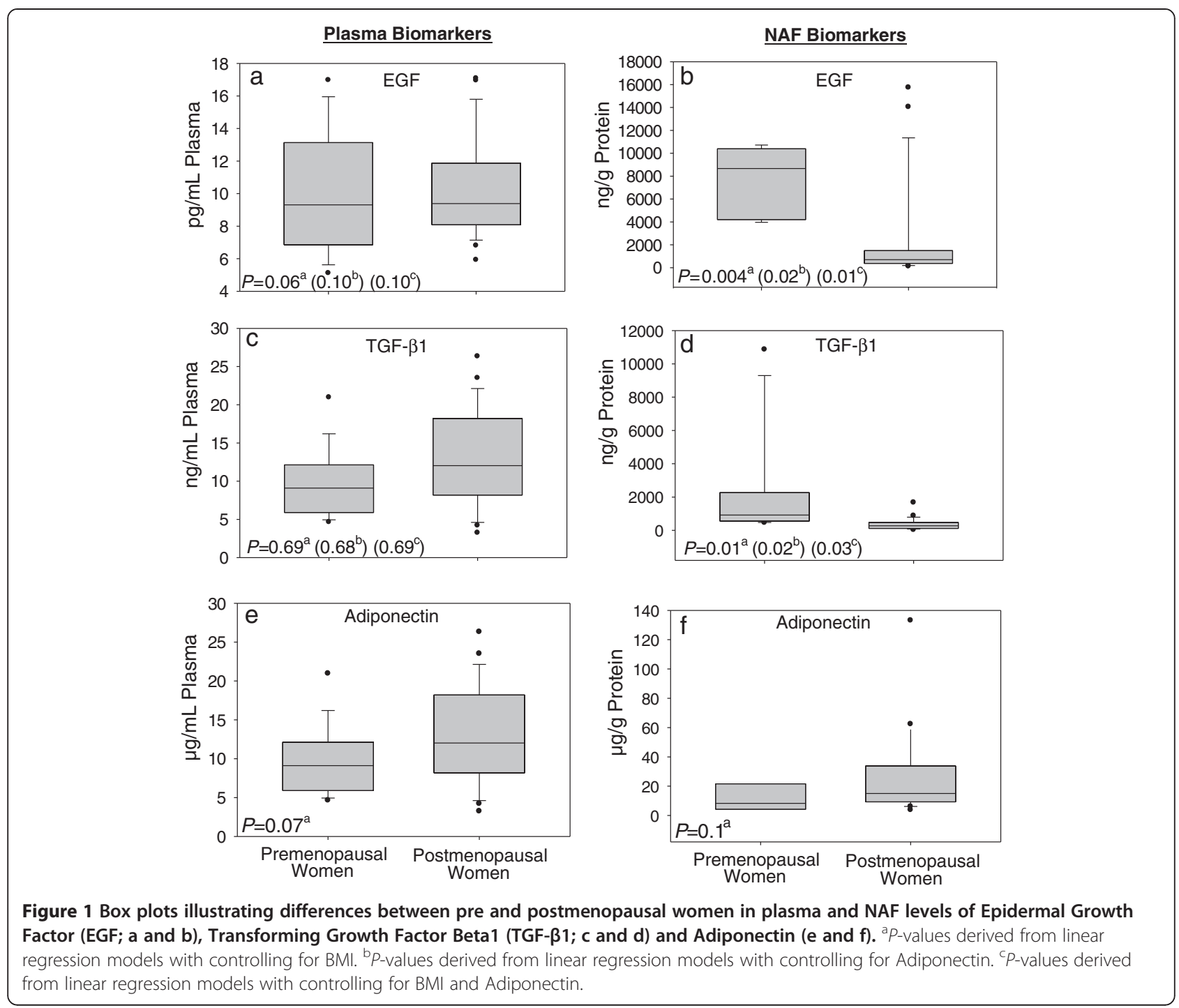

Table 2 Association between biomarker levels in NAF and plasma

\begin{tabular}{|c|c|c|}
\hline & Spearman correlation & $P$-value \\
\hline \multicolumn{3}{|l|}{ EGF } \\
\hline Premenopausal $(n=9)$ & -0.15 & 0.70 \\
\hline Postmenopausal $(n=24)$ & 0.14 & 0.51 \\
\hline
\end{tabular}

TGF- $\beta 1$

$\begin{array}{lcc}\text { Premenopausal }(n=11) & -0.35 & 0.30 \\ \text { Postmenopausal }(n=24) & 0.25 & 0.25\end{array}$

Adiponectin

\begin{tabular}{lcl} 
Premenopausal $(n=6)$ & -0.09 & 0.87 \\
Postmenopausal $(n=22)$ & 0.29 & 0.20 \\
\hline
\end{tabular}

premenopausal women, plasma adiponectin was significantly inversely associated with BMI $(P=0.02 ; \mathrm{n}=16)$. Analyses of the two-way interaction between BMI and menopausal status for plasma EGF and TGF- $\beta 1$ concentrations were statistically significant $(P=0.04$ and $P=0.01$, respectively).

\section{Discussion}

In a cohort of 43 healthy women, we measured the secreted protein biomarkers EGF, TGF- $\beta 1$, and adiponectin in matched NAF and plasma samples. Interestingly, none of the three biomarkers in NAF were correlated to levels in plasma. Further, in postmenopausal women, levels of all three potential breast cancer biomarkers in plasma were inversely correlated with BMI, but there was no relationship between BMI and these biomarkers in NAF. With our small sample size, correlation coefficients $\geq 0.45$ are necessary to determine 
Table 3 Association between biomarker levels and BMI

\begin{tabular}{|c|c|c|c|}
\hline EGF & & Spearman correlation & $P$-value \\
\hline \multicolumn{4}{|c|}{ NAF } \\
\hline & Premenopausal $(n=9)$ & -0.20 & 0.61 \\
\hline & Postmenopausal $(n=25)$ & 0.06 & 0.79 \\
\hline \multicolumn{4}{|c|}{ Plasma } \\
\hline & Premenopausal $(n=16)$ & 0.25 & 0.35 \\
\hline & Postmenopausal $(n=27)$ & -0.55 & 0.003 \\
\hline \multicolumn{4}{|c|}{ TGF- $\beta 1$} \\
\hline \multicolumn{4}{|c|}{ NAF } \\
\hline & Premenopausal $(n=11)$ & -0.23 & 0.50 \\
\hline & Postmenopausal $(n=26)$ & -0.09 & 0.68 \\
\hline \multicolumn{4}{|c|}{ Plasma } \\
\hline & Premenopausal $(n=16)$ & 0.41 & 0.11 \\
\hline & Postmenopausal $(\mathrm{n}=27)$ & -0.60 & $<0.001$ \\
\hline \multicolumn{4}{|c|}{ Adiponectin } \\
\hline \multicolumn{4}{|c|}{ NAF } \\
\hline & Premenopausal $(n=6)$ & -0.31 & 0.54 \\
\hline & Postmenopausal $(n=23)$ & 0.15 & 0.50 \\
\hline \multicolumn{4}{|c|}{ Plasma } \\
\hline & Premenopausal $(n=16)$ & -0.59 & 0.02 \\
\hline & Postmenopausal $(n=27)$ & -0.39 & 0.05 \\
\hline
\end{tabular}

statistically significant correlations between NAF and plasma or between biomarkers and BMI with $80 \%$ power. Our sample size, however, was sufficient to determine a statistically significant relationship between plasma adiponectin levels and BMI, a well-known association [13]. Therefore, this preliminary evidence suggests that NAF contains biological information distinct from plasma, despite the small sample size.

We are aware of only one other study reporting adiponectin levels in the NAF; Sauter et al. observed that 3 and 6 months after bariatric surgery, NAF adiponectin levels significantly increased in premenopausal women, but were unchanged in postmenopausal women [14]. Given the known inverse association between plasma adiponectin levels and BMI [15] and epidemiological evidence indicating an inverse relationship between adiponectin levels and breast cancer risk [11], it is interesting that NAF adiponectin levels in postmenopausal women appear to be independent of BMI in our work as well as that of Sauter et al.

To our knowledge, this is the first study to quantify TGF- $\beta 1$ in NAF. Here TGF- $\beta 1$ levels in NAF of premenopausal women were significantly higher than postmenopausal women, whereas plasma levels were similar between the two groups. These results likely reflect differential hormone levels in the breast by menopausal status.
NAF EGF levels in healthy, pre and postmenopausal women were similar to those previously reported [16-18]. Our finding of higher EGF levels in NAF of premenopausal women relative to postmenopausal women is consistent with a positive effect of sex hormones on EGF exposure in the breast [16]; as well as with other studies which have shown differences in plasma and NAF biomarkers by sex steroid hormone concentrations $[19,20]$.

While our data suggests that circulating EGF, TGF- $\beta 1$ and adiponectin in plasma are regulated differently from NAF protein levels, the main study limitation is the small sample size. Further, the premenopausal women enrolled in this study had, on average, a higher BMI compared to the postmenopausal women. This differs from the age expected BMI distribution [21], suggesting a participation bias. We attempted to adjust for this bias using adiponectin as a surrogate of metabolic disturbance [22]. After adjustment for BMI alone, adiponectin alone, or BMI and adiponectin, there were still significant differences in the NAF levels of the study proteins between pre and post-menopausal women, which were not observed in plasma. Reproductive variables such as time since lactation or last full birth may also affect NAF components [23], however, were not collected as part of the clinical study. Timing of sample collection for phase in the menstrual cycle poses another potential source of variation that was not controlled in this study. Chatterton et al., however, has demonstrated that levels of NAF proteins including EGF, cathepsin D, and interleukin- 6 were consistent throughout the phases of the menstrual cycle [24]. Therefore, it is likely that the variation in NAF protein levels in premenopausal women is a reflection of long-term hormonal (and environmental) exposures. Taken together, our findings suggest that the underlying biological factors associated with both BMI and menopausal status differentially influence protein expression in plasma as compared NAF. Future studies with larger sample sizes are warranted to develop the use of NAF as a minimally invasive strategy to identify risk factors and novel drug/prevention targets in the breast.

\section{Additional file}

\footnotetext{
Additional file 1: Figure S1. Scatter plots illustrating null associations between plasma and NAF levels in premenopausal and postmonausal women of Epidermal Growth Factor (EGF; $\mathbf{a}$ and $\mathbf{b}$ ), Transforming Growth Factor Beta 1 (TGF- $\beta 1 ; \mathbf{c}$ and $\mathbf{d}$ ) and Adiponectin (e and $\mathbf{f}$ ). The appearance of an association between NAF and Plasma levels of TGF- $\beta 1$ in postmenopausal women (d) seems to be driven by one woman with very high levels in both NAF and plasma. Figure S2. Scatter plots illustrating associations between BMI and plasma levels of Epidermal Growth Factor (EGF; a), Transforming Growth Factor Beta 1 (TGF- $\beta 1$ : b) and Adiponectin (c) in premenopausal women; between BMI and NAF levels of EGF (d) TGF- $\beta 1$ (e) and Adiponectin (f) in premenopausal women; between BMI and plasma levels of EGF (g) TGF- $\beta 1$ (h) and
} 
Adiponectin (i) in postmenopausal women; and between BMI and NAF levels of EGF (j) TGF- $\beta 1$ (k) and Adiponectin (I) in postmenopausal women. Table S1. NAF and plasma biomarker levels.

\section{Abbreviations}

BMI: Body mass index; EGF: Epithelial growth factor; NAF: Nipple aspirate fluid; TGF- 1 1: Transforming growth factor beta 1; Her-2/neu: Human Epidermal Growth Factor Receptor 2; ELISA: Enzyme-linked immunosorbent assay.

\section{Competing interests}

The authors' declared that they have no competing interest.

\section{Authors' contributions}

JAM carried out the ELISA's, drafted the manuscript, and contributed to the interpretation of the data. PAT helped to draft the manuscript and contributed to the interpretation of the data. IAH helped to draft the manuscript. AML helped to draft the manuscript. CAT helped to draft the manuscript. $\mathrm{CHH}$ carried out the statistical analysis. HSC conceived of the study design, was responsible for the coordination of the clinical trial, helped to draft the manuscript and contributed to the interpretation of the data. All authors have read and approved of the final manuscript.

\section{Acknowledgements}

We would like to thank Donna Vining and Heidi Fritz their assistance in the conduct of the clinical study.

\section{Grant support}

Department of Defense grant \# BC061529.

\section{Author details}

${ }^{1}$ The University of Arizona Cancer Center, Tucson, AZ, USA. ${ }^{2}$ Zuckerman College of Public Health, The University of Arizona, Tucson, AZ, USA.

\section{Received: 13 February 2013 Accepted: 6 April 2013}

Published: 15 April 2013

\section{References}

1. King EB, Chew KL, Petrakis NL, Ernster VL: Nipple aspirate cytology for the study of breast cancer precursors. J Natl Cancer Inst 1983, 71(6):1115-1121.

2. Wrensch M, Petrakis NL, King EB, Lee MM, Miike R: Breast cancer risk associated with abnormal cytology in nipple aspirates of breast fluid and prior history of breast biopsy. Am J Epidemiol 1993, 137(8):829-833.

3. Sauter ER, Ross E, Daly M, Klein-Szanto A, Engstrom PF, Sorling A, Malick J, Ehya $\mathrm{H}$ : Nipple aspirate fluid: a promising non-invasive method to identify cellular markers of breast cancer risk. Br J Cancer 1997, 76(4):494-501.

4. Tice JA, Miike R, Adduci K, Petrakis NL, King E, Wrensch MR: Nipple aspirate fluid cytology and the Gail model for breast cancer risk assessment in a screening population. Cancer epidemiology, biomarkers \& prevention: a publication of the American Association for Cancer Research, cosponsored by the American Society of Preventive Oncology 2005, 14(2):324-328.

5. Malatesta M, Mannello F, Bianchi G, Sebastiani M, Gazzanelli G: Biochemical and ultrastructural features of human milk and nipple aspirate fluids. J Clin Lab Anal 2000, 14(6):330-335.

6. Mannello F, Medda V, Tonti GA: Protein profile analysis of the breast microenvironment to differentiate healthy women from breast cancer patients. Expert Rev Proteomics 2009, 6(1):43-60.

7. Manello F, Medda V, Smaniotto A, Tonti GA: Intracronology of breast microenvironment: hormonal status in nipple aspirate fluid and its relationship to breast cancer. Expert Rev Endocrinol Metab 2009, 4(5):493-505.

8. Kuerer HM, Thompson PA, Krishnamurthy S, Fritsche HA, Marcy SM, Babiera GV, Singletary SE, Cristofanilli M, Sneige N, Hunt KK: High and differential expression of HER-2/neu extracellular domain in bilateral ductal fluids from women with unilateral invasive breast cancer. Clinical cancer research: an official journal of the American Association for Cancer Research 2003, 9(2):601-605.

9. Foley J, Nickerson NK, Nam S, Allen KT, Gilmore JL, Nephew KP, Riese DJ 2nd: EGFR signaling in breast cancer: bad to the bone. Semin Cell Dev Biol 2010, 21(9):951-960.
10. Muraoka-Cook RS, Dumont N, Arteaga CL: Dual role of transforming growth factor beta in mammary tumorigenesis and metastatic progression. Clin Cancer Res 2005, 11 (2 Pt 2):937s-943s.

11. Chen X, Wang Y: Adiponectin and breast cancer. Med Oncol 2011, 28(4):1288-1295.

12. Miller JATP, Hakim IA, Lopez AM, Thomson CA, Chew WM, Hsu CH, Chow HH: Safety and feasibility of topical application of limonene as a massage oil to the breast. Journal of Cancer Therapy 2012, 3:749-754.

13. Lu JY, Huang KC, Chang LC, Huang YS, Chi YC, Su TC, Chen CL, Yang WS: Adiponectin: a biomarker of obesity-induced insulin resistance in adipose tissue and beyond. J Biomed Sci 2008, 15(5):565-576.

14. Sauter ER, Mitchell JE, Kliethermes B, Crosby RD: Breast cancer biomarkers predict weight loss after gastric bypass surgery. BMC Res Notes 2012, 5:82.

15. Trujillo ME, Scherer PE: Adiponectin-journey from an adipocyte secretory protein to biomarker of the metabolic syndrome. J Intern Med 2005, 257(2):167-175.

16. Gann PH, Geiger AS, Helenowski IB, Vonesh EF, Chatterton RT: Estrogen and progesterone levels in nipple aspirate fluid of healthy premenopausa women: relationship to steroid precursors and response proteins. Cancer Epidemiol Biomarkers Prev 2006, 15(1):39-44.

17. Sauter ER, Ehya H, Babb J, Diamandis E, Daly M, Klein-Szanto A, Sigurdson E, Hoffman J, Malick J, Engstrom PF: Biological markers of risk in nipple aspirate fluid are associated with residual cancer and tumour size. Br J Cancer 1999, 81(7):1222-1227.

18. Chatterton RT Jr, Geiger AS, Mateo ET, Helenowski IB, Gann PH: Comparison of hormone levels in nipple aspirate fluid of pre- and postmenopausal women: effect of oral contraceptives and hormone replacement. J Clin Endocrinol Metab 2005, 90(3):1686-1691.

19. Maskarinec G, Ollberding NJ, Conroy SM, Morimoto Y, Pagano IS, Franke AA, Gentzschein E, Stanczyk FZ: Estrogen Levels in Nipple Aspirate Fluid and Serum during a Randomized Soy Trial. Cancer Epidemiol Biomarkers Prev 2011, 20(9):1815-1821

20. Chatterton RT Jr, Khan SA, Heinz R, Ivancic D, Lee O: Patterns of sex steroid hormones in nipple aspirate fluid during the menstrual cycle and after menopause in relation to serum concentrations. Cancer epidemiology, biomarkers \& prevention : a publication of the American Association for Cancer Research, cosponsored by the American Society of Preventive Oncology 2010, 19(1):275-279.

21. Stevens J, Cai J, Pamuk ER, Williamson DF, Thun MJ, Wood JL: The effect of age on the association between body-mass index and mortality. $N$ Engl J Med 1998, 338(1):1-7.

22. Chen SJ, Yen CH, Huang YC, Lee BJ, Hsia S, Lin PT: Relationships between Inflammation, Adiponectin, and Oxidative Stress in Metabolic Syndrome. PLoS One 2012, 7(9):e45693.

23. Gruenke LD, Wrensch MR, Petrakis NL, Miike R, Ernster VL, Craig JC: Breast fluid cholesterol and cholesterol epoxides: relationship to breast cancer risk factors and other characteristics. Cancer Res 1987, 47(20):5483-5487.

24. Chatterton RT Jr, Geiger AS, Khan SA, Helenowski IB, Jovanovic BD, Gann $\mathrm{PH}$ : Variation in estradiol, estradiol precursors, and estrogen-related products in nipple aspirate fluid from normal premenopausal women. Cancer epidemiology, biomarkers \& prevention: a publication of the American Association for Cancer Research, cosponsored by the American Society of Preventive Oncology 2004, 13(6):928-935.

doi:10.1186/2050-7771-1-18

Cite this article as: Miller et al:: Expression of epidermal growth factor, transforming growth factor- $\beta 1$ and adiponectin in nipple aspirate fluid and plasma of pre and post-menopausal women. Biomarker Research 2013 1:18. 